\title{
MUJERES MARGINADAS Y PERSEGUIDAS POR SUS CREENCIAS RELIGIOSAS EN EL PERÍODO COLONIAL NORTEAMERICANO
}

\author{
EXCLUDED AND PERSECUTED WOMEN BY THEIR RELIGIOUS BELIEFS IN THE \\ AMERICAN COLONIAL PERIOD
}

Antonia Sagredo Santos

Universidad Autónoma de Madrid

\section{RESUMEN:}

En este artículo se analiza las vidas de cuatro mujeres (Anne Hutchinson, Mary Dyer, Mary Bliss Parson, y Margaret Brent) que debido a sus creencias religiosas sufrieron persecución y intolerancia durante la América colonial. Mujeres que fueron tratadas como incomprendidas y a las que se les quitó la libertad para poder expresarse.

\section{Palabras claves:}

Anne Hutchinson, Mary Dyer, Mary Bliss Parson, Margaret Brent.

\section{Abstract:}

In this article we will analyse the lives of four women (Anne Hutchinson, Mary Dyer, Mary Bliss Parson and Margaret Brent) who suffered from persecution and intolerance in the colonial America due to their religious beliefs. They were considered as misunderstood and whose freedom of expression was removed.

\section{KEY WORD:}

Anne Hutchinson, Mary Dyer, Mary Bliss Parson, Margaret Brent. 


\section{INTRODUCCIÓN}

En 1620 se produce la llegada del "Mayflower" con los "Pilgrim Fathers" a las costas de Cape Cod, aunque es en 1607 cuando comienza la colonización de Jamestown. El pasaje de ese navío estaba compuesto por ciento dos personas, de las cuales, cuarenta y una eran disidentes religiosos que viajaban al continente americano en busca de un lugar donde poder practicar libremente sus creencias religiosas. Ese grupo fue el artífice del primer documento escrito de la historia norteamericana, el "Mayflower Compact", en el cual estamparon sus firmas el 11 de noviembre de 1620. Los firmantes del texto del Pacto eran sólo los cabeza de familia, por lo que no figuraba ninguna mujer, ya que siempre se las consideraba incluidas dentro de la unidad familiar cuyo representante legal era el hombre. La población de Nueva Inglaterra, mayoritariamente puritana, experimentó un crecimiento vegetativo constante durante todo el siglo XVII. Más de 25.000 inmigrantes cruzaron el océano antes del inicio de las Guerras Civiles en Inglaterra. La esperanza de vida de los habitantes de esta zona era de setenta años para un $20 \%$ de la población, tanto para los hombres como para las mujeres. Sin embargo, en las tierras de Virginia y Maryland, las condiciones de vida en las plantaciones de tabaco eran mucho más duras y la población sólo alcanzaba, por término medio, los cuarenta años. Sin embargo, para las mujeres la media bajaba a los treinta.

La esperanza media de vida era mayor en los territorios de Nueva Inglaterra, donde los matrimonios eran más duraderos y, por tanto, tenían un mayor número de hijos. En algunas localidades, nueve de cada diez descendientes sobrevivían y llegaban a convivir con los padres e incluso con los abuelos, como leemos en el párrafo que se presenta a continuación: Una vida más larga afectaba a las relaciones familiares. New England había sido una de las primeras sociedades en la historia constatada en la que una persona podía razonablemente anticipar que iba a conocer a sus nietos. Por lo tanto, las tradiciones particulares de familias y comunidades se mantenían vivas, literalmente, en la memoria de los habitantes más ancianos de la colonia (Divine, 1998 $41)^{1}$.

Desde el punto de vista demográfico, en Nueva Inglaterra los núcleos familiares eran más estables, ya que los puritanos solían cruzar el océano Atlántico en grupos de familias, con lo que el porcentaje entre el número de mujeres y el de hombres estaba más equilibrado que en los territorios de Virginia y Maryland, donde la mayoría de los inmigrantes que se establecieron eran varones solteros. La principal causa era

1 Traducción de la autora, véase texto original: "Longer life altered family relations. New England may have been one of the first societies in recorded history in which a person could reasonably anticipate knowing his or her grandchildren. The traditions of particular families and communities therefore remained alive, literally, in the memories of colony's oldest citizens" (Divine, 1998: 41).

Revista Internacional de Culturas y Literaturas, abril 2008 que los propietarios de las plantaciones de tabaco preferían hombres jóvenes y sin cargas familiares para trabajar en los campos. Como consecuencia, el porcentaje de mujeres era bajo y este hecho retrasaba el establecimiento y desarrollo de las unidades familiares. Hasta 1640, tanto en Maryland como en Virginia, llegaba una mujer por cada seis hombres. En 1700 esta diferencia bajó a dos mujeres por cada tres hombres. Estos primeros inmigrantes puritanos, que se establecieron como colonos, consideraban a la familia como una "pequeña comunidad". Además de sus funciones típicas, como son mantener un núcleo familiar y criar una prole, tenían unos objetivos educativos, ya que transmitían el oficio de padres a hijos, y religiosos, al ser la institución familiar el principal núcleo en el que se afianzaban y difundían sus creencias religiosas. Igualmente, la familia era la responsable del cuidado de los enfermos y ancianos.

Los puritanos llevaron a las colonias norteamericanas los valores patriarcales, subordinando la identidad legal de la mujer a la del marido, que era, indiscutiblemente, el cabeza de familia. El núcleo familiar estaba compuesto por padres, hijos, abuelos y otros familiares, a los que se sumaban los criados y aprendices, todos bajo la autoridad del padre. Solamente en el caso de que firmaran los nuevos esposos unos acuerdos prematrimoniales, todos los bienes que aportaba la mujer al matrimonio quedaban bajo su dominio; si no era así, pasaban a ser propiedad del esposo. Además, el hombre representaba a su familia en todas las actividades políticas, económicas y religiosas de la comunidad (Maier, 2003: 71)2.

En los territorios de la América colonial, la función principal de las mujeres estaba orientada a perpetuar la especie, tarea en la que entre un 1 y un $1,5 \%$ de todos los nacimientos acababa con la muerte de la madre. Estas cifras se mantuvieron durante los siglos XVI y XVII, y la tendencia no cambiaría hasta la segunda mitad del siglo XVIII, cuando comenzó a normalizarse la presencia en los partos de un médico o comadrona, el uso de los fórceps, del éter y del cloroformo para tratar de paliar el dolor de la madre en el parto.

Durante el periodo colonial norteamericano, la mujer no disfrutaba de los mismos derechos que el hombre, pues era considerada como un ciudadano de segunda y permanecía sometida toda su vida a la figura masculina. Primero estaba bajo la autoridad paterna y cuando se casaba pasaba a estar a merced de la voluntad del marido, por lo que siempre existía una subordinación legal al cabeza de familia del que dependía. Esta falta de libertad para elegir su propio destino se daba tanto entre la población blanca como en la de color (Treckel, 1996). Sin embargo, tanto la ley Inglesa como la establecida en las colonias americanas reconocía la figura de la "femme sole",

2 En las siguientes palabras se describe el papel de la mujer en la sociedad colonial norteamericana: "Women were supposed to be meek and submissive; public controversies and intellectual argumen were outside their proper sphere" (Maier, 2003: 71). 
que permitía a las mujeres adultas -solteras o viudas- conservar sus propiedades y disponer de ellas, como se refleja en el siguiente párrafo:

Las condiciones sociales abrieron la puerta a las mujeres para desempeñar unas responsabilidades que raramente se habían asumido en Inglaterra. Las viudas y unas pocas mujeres que nunca se habían casado, disfrutaron las ventajas que les ofrecía su status legal como "femme sole". Ésta era una mujer, que disfrutaba de una identidad legal independiente que se negaba a las mujeres casadas, para firmar contratos o hacerse cargo de negocios... Algunas viudas eran elegidas para administrar las propiedades de sus maridos o les legaban los bienes de sus esposos en su totalidad, en lugar de recibir solamente un tercio, el derecho tradicional de la viuda en Inglaterra (Foner, 2005: 55$)^{3}$.

De esta forma, algunas mujeres que sobrevivían a dos o tres maridos podían adquirir amplias posesiones a través de herencias y mantener su control gracias a los contratos prematrimoniales. Si no los firmaban antes del matrimonio, por la figura legal conocida como "coverture", todos sus bienes iban a parar a manos de su esposo. A pesar de la dura y difícil situación que soportó la mujer en las colonias inglesas de Norteamérica, debido principalmente a que se le negaban los derechos fundamentales de todo ser humano, hubo algunas mujeres que desafiaron la autoridad del hombre y asumieron papeles asociados a la figura masculina; llegaron incluso a destacar por sus propios méritos y pudieron defender sus propias ideas y creencias en un mundo de hombres que les era hostil. De ese reducido número de mujeres que han pasado a ser protagonistas de la historia con nombre propio vamos a presentar a continuación a algunas.

\section{ANNE HUTCHINSON}

Una de las mujeres que figura en la historia norteamericana es Anne Hutchinson, quien llega a Boston con su esposo William Hutchinson y sus quince hijos a bordo del navío "Griffen" en otoño de 1634. La pareja seguía al reverendo puritano John Cotton, quien había sido expulsado por las autoridades eclesiásticas inglesas de su parroquia. Todos venían con la intención de formar una nueva comunidad religiosa en tierras norteamericanas, en las que pudieran practicar su fe abiertamente sin sufrir persecuciones. En esae época, los puritanos no podían expresarse libremente en Inglaterra y muchos de ellos optaron por emigrar a los territorios británicos del

3 Texto original: "Social conditions opened the door to roles women rarely assumed in England Widows and the few women who never married took advantage of their legal status as 'femme sole'. A woman alone, who enjoyed an independent legal identity denied to married women, to make contracts and conduct business... Some widows were chosen to administer their husband's estates or were willed their husband's property outright, rather than receiving only the one-third 'dower rights' traditional in England" (Foner, 2005: 55). continente americano. El esposo de Anne Hutchinson, William, era un floreciente comerciante inglés que contaba con recursos económicos suficientes para comprar en Boston una granja de 600 acres. Los Hutchinson pronto pasaron a ocupar un puesto destacado en la sociedad de Massachusetts debido a su holgada economía. Por su parte, Anne era hija de un clérigo inglés, quien fue sentenciado a sufrir arresto domiciliario por criticar públicamente a la iglesia establecida. Así, al no poder ejercer su magisterio en su parroquia, se volcó en la educación de sus hijos, a quienes les inculcó unas firmes creencias religiosas y su gran interés y respeto por la teología. En Boston, Mrs. Hutchinson ejerció como comadrona y su trabajo era muy apreciado, pero pronto comenzó a celebrar reuniones en su casa, aunque en un principio sólo con mujeres. Sin embargo, estos encuentros iban a inquietar a los magistrados puritanos, al ir ampliándose e incorporándose hombres a ellos. Los comerciantes eran los más fervientes seguidores de Anne y también se encontraban entre sus defensores algunos hombres que ocupaban cargos públicos. Todos ellos apoyaban incondicionalmente el duelo que mantenía Mrs. Hutchinson con las autoridades de la colonia.

En el siglo XVII no se veía apropiado que una mujer enseñara a hombres y mucho menos si se trataba de temas religiosos. Las leyes de la Bahía de Massachusetts se basaban en las enseñanzas bíblicas y consideraban que las mujeres no debían pronunciarse ni expresar sus opiniones en público, aunque, como ocurría en el caso de Anne, se tratara de una mujer inteligente y con un don de palabra fuera de lo corriente. La confrontación entre Anne Hutchinton y las autoridades eclesiásticas puritanas iba siendo cada vez más profunda, ya que ella sugería que el individuo podía conocer los deseos de Dios directamente, así como recibir su revelación sin necesidad de acudir a las autoridades eclesiásticas. Asimismo, propugnaba que la salvación era un regalo de Dios a los elegidos y que no se podía obtener sólo con el esfuerzo humano. Esta interpretación amenazaba directamente al papel que desempeñaban los ministros como intérpretes de la Biblia. Como consecuencia, a medida que aumentaba su popularidad, se incrementaba la oposición de la jerarquía eclesiástica puritana, hasta que llegó a ser acusada de sedición, desacato a la autoridad y herejía. En Massachusetts la Iglesia y el Estado se apoyaban mutuamente, y ambos grupos vieron peligrar su propio liderazgo con las ideas que difundía Anne Hutchinson, que encontraban numerosos adeptos entre los habitantes de la colonia. Por ello, los magistrados del Tribunal que la juzgó afirmaban que Anne constituía una gran amenaza para la comunidad. No obstante, Anne llegó a cuestionar la autoridad y los conocimientos de teología de algunos de los más respetables eclesiásticos de la colonia, como justificación para divulgar sus propias ideas, que fueron conocidas como "Antinomianism", que los puritanos definían como algo que iba en contra de las leyes "of human governance" (Martin, 1997: 56). Sus ideas se basaban más en la divina inspiración que en la Biblia o en los clérigos. Por lo tanto, no se fundaban 
directamente en las Sagradas Escrituras. En consecuencia, los líderes espirituales puritanos consideraban muy peligrosas las enseñanzas que proclamaba Anne, ya que eran subjetivas y no se podían verificar porque la verdad de una persona era tan válida como la de cualquier otra. El gobernador John Winthrop pensaba que las ideas que defendía Hutchinson invitaban a la anarquía civil y religiosa (Divine, 1998: 29). Sin embargo, al mismo tiempo que Winthrop persiguió y envió al exilio a Anne Hutchinson por sus acciones, escribía palabras de alabanza y admiración hacia ella, y afirmaba que era "una mujer con un vivo ingenio y un espíritu valiente" (Foner, 2005: 71).

Finalmente, tuvo que defenderse en un juicio que se celebró en 1637 y duró dos días completos. Su principal acusación era el haberse atrevido, como mujer, a hablary enseñar a los hombres en público. Su gran crimen consistía en haber usurpado a la autoridad masculina su indiscutible preponderancia, como recoge Martin (1997: 56): "era una mujer que no se adaptaba a aquella sociedad". Además, durante el juicio, demostró al Tribunal que conocía perfectamente las Sagradas Escrituras. Anne Hutchinson llevó a cabo brillantemente su propia defensa con gran inteligencia y elocuencia, afirmando que conocía la palabra de Dios "por una inmediata revelación", ya que ella oía una voz que le hablaba. La declaración que realizó se consideró herética y fue, finalmente, condenada al exilio; ella y sus seguidores se marcharon a Rhode Island, como se recoge en los estudios de Frost-Knappman y Collen-DuPont (1997) y LaPlante (2004). En la primavera de 1638, Anne Hutchinson abandonó la Bahía de Massachusetts, donde solamente había vivido durante ocho años, pero dejó una gran huella en la cultura religiosa de la colonia, ya que un gran número de sus seguidores pasaron a compartir las creencias de los cuáqueros. Su refugio fue la más tolerante Providence Plantation, Rhode Island, fundada por Roger Williams unos años antes. Anne ayudó a establecer la comunidad de Portsmouth en la región que se había fundado anteriormente como la Colonia Real de New Hamshire (Morison, 1983: 28)4.

Los territorios de la Bahía de Massachusetts constituían un paraíso de tolerancia si los comparamos con la tierras inglesas de donde provenían los primeros colonos. Sin embargo, para los disidentes y para todos aquéllos que no aceptaban la ortodoxia puritana, como los "Antonomians", las autoridades de la colonia se mostraban tan intolerantes como lo había sido el monarca inglés Carlos I o el arzobispo Laud. Como consecuencia de su actitud, muchos se vieron obligados a establecerse en otros territorios vecinos, y comenzó asíla colonización de amplias zonas de la costa atlántica del noroeste. Después de la muerte de su marido, William Hutchinson, Anne se fue a vivir a Nueva

4 A continuación se presenta la emigración forzada de Boston de Mrs. Hutchinson y del Reverendo Williams. Texto original: "Anne Hutchinson of Boston, who set up as a prophetess, and the Rev. Roger Williams, who differed with Bay authorities on many matters, were banished and on Narragansett Bay formed settlements wchich federated as Rhode Island and Providence Plantations in 1644" (Morison, 1983: 28).
Ámsterdam, donde tuvo un trágico final. En 1643 ella y cinco de sus hijos murieron a manos de los indios. Las tribus de la zona declararon la guerra a los colonos, como consecuencia de la decisión del gobernador William Kieft de arrebatarles sus tierras más fértiles. El conflicto bélico duró tres años, de 1640 a 1643, y arrojó un total de 1.000 indios y 200 colonos muertos. Casi tres siglos después, en 1922 se erigió una estatua en su honor en la ciudad de Boston, y en 1945 la Asamblea Legislativa revocaba la prohibición que se había dictado en su día contra Anne Hutchinson, por la que se le impedía establecerse en Massachusetts. En la actualidad, es recordada como una firme y convencida abogada de la libertad religiosa y de los derechos de la mujer.

\section{MARY DYER}

En 1638, cuando la iglesia de Boston excomulgó a Anne Hutchinson, Mary Dyer fue una de las personas que estuvo a su lado y la acompañó en aquellos difíciles momentos como signo de solidaridad. Veintidós años después, Mary volvería a actuar de acuerdo con sus propios principios sin importarle las consecuencias, aunque la defensa de sus creencias religiosas la llevaría a morir en la horca. Mary Dyer vivíó en Boston, Bahía de Massachusetts, y era una de las fieles seguidoras de Anne Hutchinson. En 1659, Mrs. Dyer supo que dos de sus amigos cuáqueros, Marmaduke Stepenson y William Robinson, habían sido detenidos y estaban en prisión. Ella los visitó en la cárcel, y también fue detenida y encarcelada. Posteriormente, los tres fueron expulsados de la colonia y advertidos de que no deberían volver de su exilio, a menos que quisieran ser colgados.

Sin embargo, Dyer, Stepenson y Robinson volvieron de nuevo a la Bahía de Massachusetts, donde fueron a prisión de nuevo por "rebelión, sedición y presuntuosa intromisión" y por "socavar al gobierno". Todos ellos comparecieron ante el Tribunal General el 19 de octubre de 1659 y reconocieron que eran los mismos que habían sido expulsados de la colonia un año antes. Atacaron a los miembros del Tribunal llamándolos "Inquisidores Papistas" del siglo XIII. Finalmente, expresaron el agravio que suponía pensar que los puritanos que habían escapado de una persecución en Inglaterra eran ahora los que perseguían a los cuáqueros. La sentencia de Dyer fue protestada por la propia Mary, por su esposo William, por su hijo, por el gobernador John Winthrop Jr. de Connecticut y el gobernador Thomas Temple de Nueva Escocia.

El gobernador John Endecott dictó la misma sentencia para los tres acusados: “Vd. irá desde aquí al lugar de donde vino [la prisión] y de allí al lugar de la ejecución, y allí se le colgará hasta que muera". Mary, cuando conoció la sentencia, permaneció serena y dijo solamente, "The Will of the Lord be done" (iQue se haga el deseo de Dios!). Cuando llegó el día de su ejecución, Dyer, Stephenson y Robinson desfilaron acompañados por una compañía de soldados tocando los tambores hacia el lugar de 
la ejecución. Dyer, como sus compañeros, estaba en el cadalso con la cuerda alrededor del cuello. Stepenson y Robinson fueron colgados pero Mary Dyer, ante su sorpresa, se libró de la horca; se le concedió vivir en libertad cuarenta y ocho horas más, y se le permitió salir de la jurisdicción; si, después de este tiempo, se la encontraba de nuevo en la zona, sería ejecutada. Mary Dyer disfrutó esa libertad inesperada durante siete meses, después de los cuales volvió de nuevo a la Bahía de Massachusetts, donde fue detenida y encarcelada. El 31 de mayo de 1660, ella reconocía ante el Tribunal General y el gobernador Endecott ser Mary Dyer y no acatar las leyes de los Puritanos. Ese mismo día, el Tribunal reunido acuerda por unanimidad que Mary debe ser castigada a morir por haber vuelto de nuevo a esa jurisdicción de la que había salido para ir al exilio. Finalmente, Mary Dyer muere en la horca el 1 de junio de 1660. Ella llegó a ser considerada una mártir por defender su ideal de que "existiera un mundo en armonía" (Martin, 1997: 82).

Mary Dyer fue declarada culpable y murió ejecutada en 1660 por practicar su fe cuáquera; se convirtió así en una víctima de la falta de libertad religiosa que se producía en la colonia de la Bahía de Massachusetts, que había sido establecida para asegurar la libertad religiosa de los fundadores puritanos. Esta libertad religiosa no se extendió a los disidentes; todos ellos eran frecuentemente echados de forma enérgica de la colonia, como recoge en su estudio Chu (1996). En 1959, el Tribunal General de Massachusetts conmemoró y reinterpretó las acciones de Mary Dyer y ordenó erigir una estatua conmemorativa de siete pies de altura para ser colocada en los jardines de la Boston State House con una inscripción en la que se lee: "Testigo de la libertad religiosa" ("Whitness for religious Freedom").

El tratamiento que dispensaron a los cuáqueros en Massachusetts empañó la reputación de la colonia en Inglaterra, ya que se la identificaba como un territorio en el que se practicaba la persecución religiosa. Como consecuencia, en 1660, cuando el rey inglés Carlos II restauró la monarquía, ordenó a Massachusetts que reconociera la libertad de conciencia de todos los protestantes. Sin embargo, a pesar de que las muertes disminuían, los esfuerzos por eliminar a los cuáqueros continuaban, así como los ataques a los baptistas. Pasarían aún muchos años hasta que la tolerancia religiosa llegase a Massachusetts.

\section{MARY BLISS PARSONS}

En el siglo XVII, en Nueva Inglaterra, prácticamente todos creían en la existencia de las brujas y multitud de mujeres iban a ser juzgadas por ejercer prácticas relativas a la brujería. Generalmente, se trataba siempre de mujeres, y sólo en algunos casos aislados fueron hombres los procesados. Se suponía que todas estas personas habían firmado un pacto con el diablo y se consideraba que ellas eran las causantes de todo tipo de desgracias. La mayor parte eran condenadas a morir colgadas sin mediar juicio alguno. Sobre estas persecuciones hay abundantes testimonios. En este ensayo vamos a centrarnos en la figura de Mary Bliss Parsons, quien logró que fuera reconocida su inocencia en uno de estos juicios acusadores.

En 1646, Mary y Joseph se casan en la ciudad de Hartford y, después de vivir varios años en Springfield, se trasladaron a Northampton con sus tres hijos. La familia regentaba la taberna de la localidad. Al poco tiempo de instalarse allí, Mary B. Parsons dió a luz un hijo, el primer niño nacido en el pueblo. Al mismo tiempo, otra pareja tuvo otro vástago que murió a las dos semanas de edad, hecho muy frecuente en aquellos días, y cuya muerte se achacó a los ritos de brujería de Mary. Además, se la consideró responsable de la muerte de algunas cabezas de ganado y de la enfermedad de varios vecinos de su comunidad. Las acusaciones se intensificaron cuando algunos conocidos testificaron en su contra pero, afortunadamente para ella, tuvo otros vecinos que testificaron a su favor. Después de un largo proceso, celebrado en la ciudad de Boston, el 13 de Mayo de 1675 el jurado declaraba inocente a Mary B. Parsons de practicar la brujería.

El caso de Mrs. Parsons no era único; las persecuciones por brujería continuaron y alcanzaron su punto más álgido en el pueblo de Salem -hoy día- la ciudad de Danvers-; el fenómeno se extendió por todas los localidades del condado de Essex. Esta persecución alcanzaba mayoritariamente a las mujeres, aunque también a algunos niños y jóvenes. Las mujeres de mediana edad eran las que más fácilmente protagonizaban esas acusaciones. Los motivos podían ser celos, animosidad personal, enemistades, viejas rencillas, venganzas personales y familiares, etc. En algún momento hubo 170 acusadas por brujería en prisión en las ciudades de Ipswich, Salem, Boston y Cambridge. Entre los meses de junio y septiembre de 1692, las autoridades colgaron a 19 personas y cuatro más murieron en la cárcel esperando el juicio. Sin embargo, no fue hasta la llegada de un nuevo siglo y un cambio de mentalidad, cuando tocó a su fin la racha de ejecuciones por brujería en la colonia de Nueva Inglaterra.

\section{MARGARET BRENT}

En los territorios de Virginia y Maryland la situación de la mujer era muy diferente. El número de féminas era muy escaso, por lo que a menudo se emparejaban de forma no deseada, bien con sus amos o con otros hombres que abusaban de su poder o posición para obligarlas a relacionarse con ellos. Sin embargo, hubo algunas mujeres que adquirieron una mayor influencia social al detentar la propiedad de la tierra, por permanecer solteras o viudas. Una de las mujeres más representativas y que adquirió una gran influencia social al detentar la propiedad de sus tierras fue Margaret Brent (1601-1671). Ella era una mujer soltera, que no llegó a casarse nunca, y que ejerció 
unos poderes impensables para una fémina en las colonias británicas de Norteamérica. Margaret compró tierras, dirigió sus propias plantaciones y actuó como abogada ante los tribunales (Foner, 2005: 55).

Margaret había nacido en Gloucester, Inglaterra, en 1601. Era hija de Richard Brent, Lord de Admington y Stroke, y de Elizaberth Reed, hija del Lord de Tusburie y Witten, quienes formaban una rica familia católica inglesa. En el mes de octubre de 1938, se embarcó en Plymouth con su hermana Mary y sus hermanos Giles y Fulke rumbo a las colonias norteamericanas; llegó a las costas de Maryland el 22 de noviembre de 1638. Miss Brent era una mujer inteligente y decidida que, cuando llegó a la nueva tierra, presentó al Gobernador Leonard Calvert las cartas que le había entregado Lord Baltimore, en las se solicitaban tierras y privilegios para las dos hermanas. El 4 de octubre de 1639, Margaret obtuvo de la Asamblea una patente para setenta y un acres de tierra en la ciudad de St. Mary, terrenos a los que denominó "Sister's Freehold".

Tanto las leyes de las colonias británicas en los territorios de Norteamérica como la ley inglesa reconocían la figura de la "femme sole", por la que se permitía a mujeres adultas solteras o viudas poseer y hacerse cargo de sus propiedades ellas mismas; de este modo, pasaban a desempeñar el cargo de cabeza de familia y adquirían una identidad legal independiente que se negaba a las mujeres casadas. Así, Margaret se convertía en la primera mujer que llegaba a poseer tierras a su nombre en los territorios de Maryland. Posteriormente, la extensión de sus propiedades se fue incrementando, hasta llegar a superar los 1000 acres. En 1646, cuando el Gobernador Calvert vuelve a Maryland desde Virginia, donde había permanecido durante un tiempo, se declaró una rebelión liderada por William Claiborne, que pudo ser sofocada gracias al grupo de voluntarios armados que reunió la propia Margaret. A su muerte, en 1647, Calvert dejó a Miss Brent como albacea testamentaria y le encargó la explotación de sus tierras y bienes (Martin, 1997: 64). El 21 de enero de 1648, Margaret solicitó formar parte de la Asamblea de Maryland, así como el derecho al voto, ya que cumplía las dos condiciones necesarias para poder votar, ser propietaria de tierras y pagar impuestos. Sin embargo, no tuvo éxito en su petición; la suya llegó a considerarse en aquellos momentos, por parte de los legisladores, todos hombres, como una demanda subversiva y un intento de alterar el orden natural de las relaciones humanas. En aquellos años, era inconcebible que una mujer pudiera formar parte de algún órgano representativo de la comunidad y que tomara decisiones, como recogen en sus trabajos Julia C. Spruill (1934) y Ann Jansen (1990). Margaret, resentida por no poder ejercer su derecho al voto, dejó Maryland en 1650 y se estableció en unas tierras más hacía el oeste, "Westmoreland Country", en Virginia, a las que ella llamó "Peace". Con el paso de los años, sus posesiones fueron en aumento, ya que tenía plantaciones en Maryland y en Virginia, y llegó a convertirse en una persona muy poderosa. Sus tierras eran muy prósperas y ella era una mujer de negocios con mucho éxito. Incluso llegó a prestar dinero a los inmigrantes recién llegados y siguió comprando tierras y esclavos, ganándose así el respeto de toda la comunidad. Margaret Brent murió en 1671 en una de sus plantaciones.

\section{CONCLUSIONES}

Estas cuatro mujeres que hemos analizado lucharon por integrarse en la sociedad colonial norteamericana en el sigloXVIIy poder expresar libremente susideas y creencias religiosas. Sin embargo, todas fueron unas incomprendidas y pagaron con el exilio su atrevimiento, e incluso alguna de ellas, con su propia muerte. Posteriormente, una vez finalizada la etapa colonial con la independencia de las colonias Norteamericanas de la Corona Británica, tampoco mejoró la situación de la mujer en la sociedad ni se consiguieron avances sustanciales. Tendrían que pasar muchos años todavía para que el ejemplo de estas mujeres pudiera extenderse entre la población femenina de la joven república norteamericana, y así fueran recompensados los esfuerzos realizados por todas ellas para poder expresar libremente sus ideas, tanto religiosas como políticas.

Hubo que dejar pasar más de cien años para ver cómo, en la últimas décadas del siglo XVIII, gracias a la labor desarrollada por un nutrido grupo de fervientes defensoras de la incorporación de la mujer a la sociedad norteamericana, se registraron unos avances que revirtieron en la mejora de las condiciones de vida de todo el género femenino. En 1789, Massachusetts sería el primer estado en el que se requería a sus ciudadanos pagar la educación tanto de los hombres como de las mujeres. Como consecuencia de estos cambios, un buen número de niñas se incorporaron a las escuelas y, posteriormente, pasaron a formar parte de un nutrido grupo de mujeres que desarrollaron su profesión como escritoras, poetisas, pintoras, etc., y que siguieron la estela dejada por estas primeras mujeres que hemos estudiado en este ensayo, quienes ya se atrevieron a reivindicar una equiparación de derechos entre hombres y mujeres. Sin embargo, la lucha por alcanzar esta igualdad entre los dos sexos en la joven nación norteamericana no había hecho nada más que comenzar y aún le quedaría un largo recorrido hasta llegar a alcanzar los objetivos deseados.

\section{REFERENCIAS BIBLIOGRÁFICAS}

Chu, J. M., Neighbours, Friends, or Madmen: The Puritan Adjustment to Quaquerism in Seventeenth-Century, Massachusetts Bay, Westport, Greenwood Press, 1985.

Divine, R. A., et al., America Past and Present, Nueva York, Longman, 1998.

Fleming, T., Liberty! The American Revolution, Nueva York, Viking, 1997.

Foner, E., Give Me Liberty. An American History, Nueva York, W. W. Norton \& Co., 2005. 
Frost-Knappman, E. y Cullen-Dupont, K., Women's Rights on Trial: 101 Historic Trials from Anne Hutchinson to the Virginia Military Institute Cadets, Detroit, Gale, 1997.

Jansen, A., “Us This Justice?: A Woman Plea in Colonial Maryland Puts Margaret Brent Ahead of Her Time", en Annapolitan, junio de 1990, pp. 47-49.

Laplante, E., American Jezebel: The Uncommon Life of Anne Hutchinson, the Woman Who Defied the Puritans, Nueva York, Harperr Collins, 2004.

Maier, P., et. al., Inventing America. A History of the United States, Nueva York, Norton \& Co., 2003.

Martin, J. K., et al., America and His Peoples. A Mosaic in the Making, Nueva York, Longman, 1997.

Morison, S. E., et al., A Concise History of the American Republic, Nueva York y Oxford, Oxford University Press, 1983.

Spruill, J. C., “Mistress Margaret Brent, Spinster”, Maryland Historical Magazine, 29, diciembre de 1934, pp. 259-269.

Treckel, P. A., To Comfort the Heart: Women in Seventeenth-Century America, Nueva York, Twayne, 1996. 